\title{
Intracellular water motion decreases in apoptotic macrophages after caspase activation
}

\author{
S Hortelano', ML García-Martín², S Cerdán², A Castrillo', \\ AM Alvarez ${ }^{3}$ and L Boscá ${ }^{*}, 1$ \\ ${ }^{1}$ Instituto de Bioquímica (Centro Mixto CSIC-UCM), Facultad de Farmacia, \\ Universidad Complutense. 28040 Madrid, Spain \\ 2 Instituto de Investigaciones Biomédicas Alberto Sols (CSIC), Arturo Duperier \\ 4, 28029 Madrid, Spain \\ ${ }^{3}$ Centro de Citometría de Flujo y Microscopía Confocal, Facultad de Farmacia, \\ 28040 Madrid, Spain \\ * Corresponding author: L Boscá, Instituto de Bioquímica, Facultad de \\ Farmacia, 28040 Madrid, Spain. \\ Fax: 3491544 7254; E-mail: bosca|@eucmax.sim.ucm.es
}

Received 21.12.00; revised 16.5.01; accepted 22.5.01

Edited by S Lipton

\section{Abstract}

Triggering of the macrophage cell line RAW 264.7 with lipopolysaccharide and interferon- $\gamma$ promoted apoptosis that was prevented by inhibitors of type 2 nitric oxide synthase or caspase. Using ${ }^{1} \mathrm{H}$ NMR analysis, we have investigated the changes of the intracellular transverse relaxation time $\left(T_{2}\right)$ and apparent diffusion coefficient (ADC) as parameters reflecting the rotational and translational motions of water in apoptotic macrophages. $T_{2}$ values decreased significantly from 287 to $182 \mathrm{~ms}$ in cells treated for $18 \mathrm{~h}$ with NO-donors. These changes of $\mathrm{T}_{2}$ were prevented by caspase inhibitors and were not due to mitochondrial depolarization or microtubule depolymerization. The decrease of the intracellular values of $\mathrm{T}_{2}$ and $\mathrm{ADC}$ in apoptotic macrophages was observed after caspase activation, but preceded phosphatidylserine exposure and nucleosomal DNA cleavage. The changes of water motion were accompanied by an enhancement of the hydrophobic properties of the intracellular milieu, as detected by fluorescent probes. These results indicate the occurrence of an alteration in the physicochemical properties of intracellular water during the course of apoptosis. Cell Death and Differentiation (2001) 8, 1022-1028.

Keywords: ${ }^{1} \mathrm{H}$ NMR; apoptosis; macrophage; nitric oxide; caspases

Abbreviations: ADC, apparent diffusion coefficient; $m \mathrm{CICCP}$, m-chlorophenylhydrazone carbonylcyanide; GSNO, S-nitrosoglutathione; IFN $\gamma$, interferon- $\gamma$; LPS, lipopolysaccharide; NOS, nitric oxide synthase; PEG, poly(ethylene)glycol (6000); PI, propidium iodide; $\mathrm{T}_{2}$, transverse relaxation time; $1400 \mathrm{~W}, \mathrm{~N}-8,3$-(aminomethylbenzyl)acetamidine

\section{Introduction}

Macrophages participate actively in host defense through the recruitment of additional inflammatory cells, release of pro-inflammatory cytokines and immune mediators, and local synthesis of reactive molecules that exert cytostatic and cytotoxic effects against pathogens and tumor cells. ${ }^{1-3}$ At the end of the inflammatory response, the cells that have been engaged in the process are removed, mainly through activation-dependent apoptosis. ${ }^{1,4-6}$ This mechanism has been considered of importance to avoid the development of parasitic strategies by potential intracellular pathogens. ${ }^{7,8}$ In particular, the biologically active molecules released by activated macrophages, among them reactive oxygen species, nitrogen intermediates and prostaglandins, elicit profound apoptotic effects in many cell types when added exogenously at concentrations in the range measured after inflammatory activation. ${ }^{3,9,10}$ In macrophages, the apoptotic phenotype shows a time-dependent pattern of sequential alterations in several parameters, such as the loss of cell adhesion and plasma membrane phospholipid assymmetry, the disorganization of the cytoskeleton and the internucleosomal DNA fragmentation, due to the activation of caspases. ${ }^{11-13} \mathrm{NO}$-dependent apoptotic signaling has been well characterized in macrophages and involves the release of mitochondrial mediators that activate caspase 9 and downstream executioner caspases, and is abrogated by the inhibitors of nitric oxide synthase and caspase. ${ }^{13-16}$

Knowledge of the intracellular signaling pathways that govern the apoptotic process has experienced major advances in recent years; however, the consequences of caspase activation on changes in intracellular structural and functional parameters have received less attention. Thus, only a relationship between apoptosis and ${ }^{1} \mathrm{H}$ NMR observable lipid resonance has been described for cell lines in culture and for rat brain glioma in vivo. ${ }^{17,18}$ Using the water molecule as a sensor of the physicochemical properties inside the cell, we performed ${ }^{1} \mathrm{H}$ NMR analysis of the intracellular medium during apoptosis. The transverse relaxation time $\left(\mathrm{T}_{2}\right)$ and the apparent self diffusion coefficient (ADC) of intracellular water were measured as indicators of its rotational and translational motions and of its interactions with macromolecules and subcellular organelles, respectively. ${ }^{19-22}$ Here we show that intracellular $\mathrm{T}_{2}$ and $\mathrm{ADC}$ values decreased significantly after caspase activation in macrophages, indicating slower rotational and translational motions of water during apoptosis. These results reveal that general physicochemical properties of the cell are modified during apoptosis and that changes in the magnetic properties of water, as detected by Magnetic Resonance Imaging methods, might be used to identify apoptotic areas in tissues of intact live organisms. 


\section{Results}

\section{NO induces apoptosis in RAW 264.7 cells}

Macrophages activated with low doses of LPS and IFN $\gamma$ expressed the high-output NO-synthesizing enzyme NOS-2 as determined by Western blot. ${ }^{1,23}$ Under these activation conditions, apoptosis was strictly dependent on the synthesis of nitric oxide since it was prevented by the specific NOS-2 inhibitor $1400 \mathrm{~W}^{24}$ (Figure 1). Apoptosis was also induced by treatment of macrophages with the nitric oxide donor GSNO, bypassing the steps of plasma membrane-receptor signaling and expression of NOS-2 (Figure 1B,C). This NO-dependent apoptosis was inhibited when cells were treated with $20 \mu \mathrm{M}$ of the broad caspase inhibitor z-VAD.fmk. Analysis of the DNA laddering of sorted apoptotic populations characterized by flow cytometry confirmed the validity of this method (Figure 1B).

\section{The intracellular ${ }^{1} \mathrm{H}$ NMR spectra was modified during apoptosis}

NO-dependent apoptosis in macrophages involved the release of cytochrome $c{ }^{15}$ the activation of caspases, the exposure of phosphatidylserine residues in the plasma membrane and DNA fragmentation. ${ }^{25}$ To investigate whether this plethora of changes might affect the overall physicochemical properties of the intracellular milieu, we monitored the dynamics of intracellular water with ${ }^{1} \mathrm{H}$ NMR during NO- induced apoptosis, correlating the results obtained using this non-invasive approach with those derived from more conventional techniques. The $\mathrm{T}_{2}$ values of intracellular water in RAW 264.7 cells undergoing GSNO-dependent apoptosis ( $81 \%$ of the cells) decreased $37 \%$ with respect to the viable counterparts (Figure 2A,B). Stimulation of control cells for 10 min with the inner mitochondrial membrane potential uncoupling drug $m \mathrm{CICCP}$ increased slightly $\mathrm{T}_{2}$ in apoptotic cells were not due to the loss of mitochondrial integrity characteristic of most apoptotic processes. ${ }^{26-28}$ Moreover, the decrease of $T_{2}$ in apoptotic cells was prevented by the caspase inhibitor z-VAD.fmk, suggesting that the proteolytic action mediated by caspases preceded the changes in $\mathrm{T}_{2}{ }^{11,29,30}$ The reduction of $\mathrm{T}_{2}$ after caspase activation was not specific for RAW 264.7 macrophages since in Jurkat T cells GSNO and dexamethasone, well known promoters of apoptosis, ${ }^{27,28}$ also decreased $\mathrm{T}_{2}$ significantly (Figure $2 \mathrm{C}$ ). Moreover, induction of apoptosis in macrophages challenged with LPS and IFN $\gamma$ reproduced the fall in $T_{2}$, and this effect was completely inhibited when cells were incubated with 1400W (Figure 2D). To distinguish the effect of apoptosis on $\mathrm{T}_{2}$ values from a more general alteration of cytoskeletal organization cells were treated with colchicine, to favor microtubule depolymerization, and z-VAD.fmk to inhibit caspases. Whereas colchicine decreased $T_{2}$, the simultaneous incubation with z-VAD.fmk inhibited apoptosis and maintained $T_{2}$ values despite the loss of microtubule structure (Figure 2D).
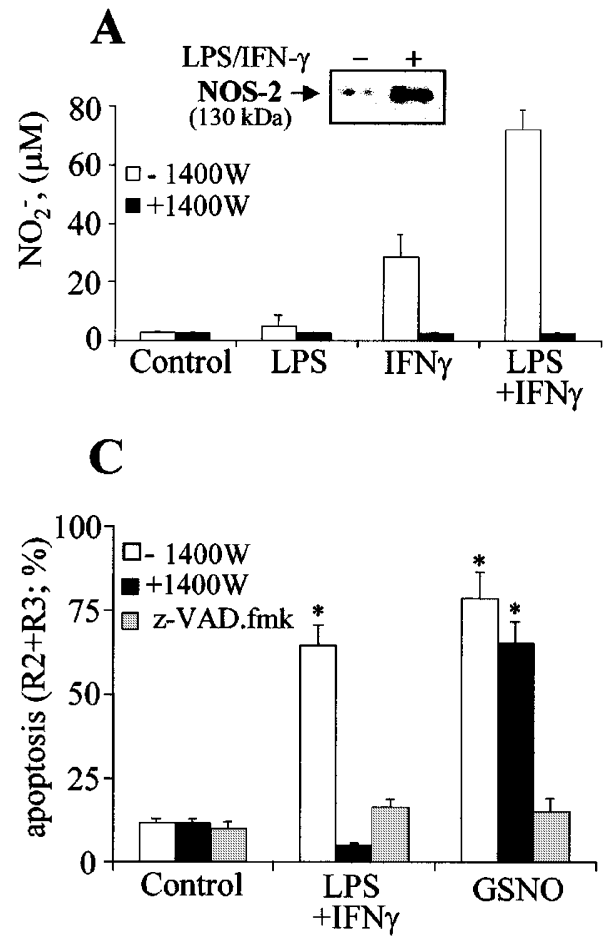

\section{B}

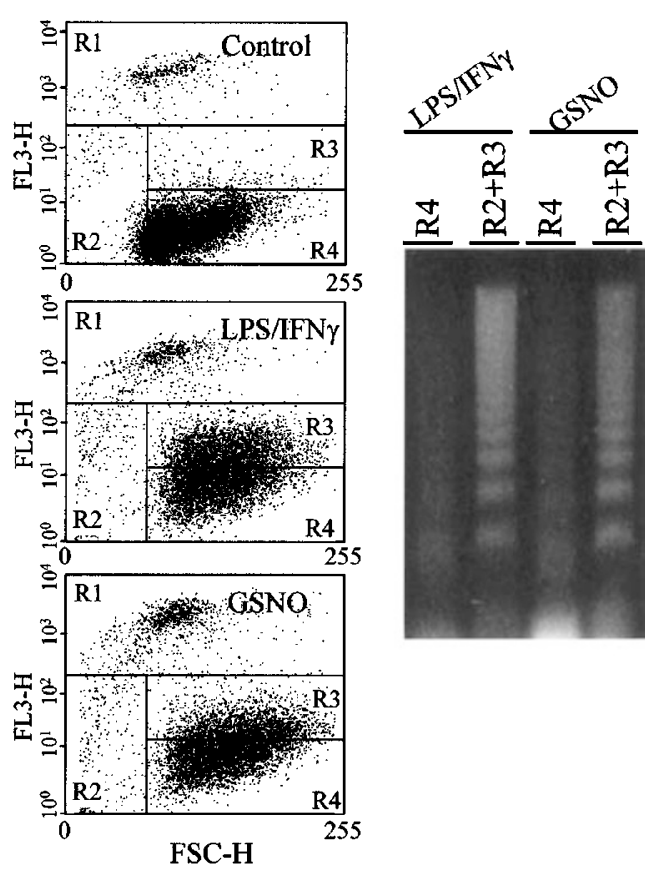

Figure 1 Induction of apoptosis in macrophages by NO. RAW 264.7 cells were incubated for $18 \mathrm{~h}$ with $200 \mathrm{ng} / \mathrm{ml}$ of LPS and $20 \mathrm{U} / \mathrm{ml}$ of $\mathrm{mIFN} \gamma$. The expression of NOS-2 and the synthesis of NO were determined. Incubation of cells with $100 \mu \mathrm{M}$ of the NOS-2 inhibitor $1400 \mathrm{~W}$ suppressed the release of NO measured as nitrite accumulation in the culture medium (A). Apoptosis was determined by flow cytometry of propidium iodide stained cells incubated for $18 \mathrm{~h}$ with LPS and IFN $\gamma$, or for $8 \mathrm{~h}$ with $1 \mathrm{mM}$ of the NO-donor GSNO (B). Sorting of cells gated in R2 plus R3 regions confirmed their apoptotic nature as deduced by DNA laddering analysis. The apoptosis observed in cells treated with LPS and IFN $\gamma$ or with GSNO was NO-dependent and inhibited by $20 \mu \mathrm{M} z-\mathrm{VAD}$.fmk (C). Results show the mean \pm S.E. of three experiments. ${ }^{*} P<0.001$ with respect to the corresponding control condition 

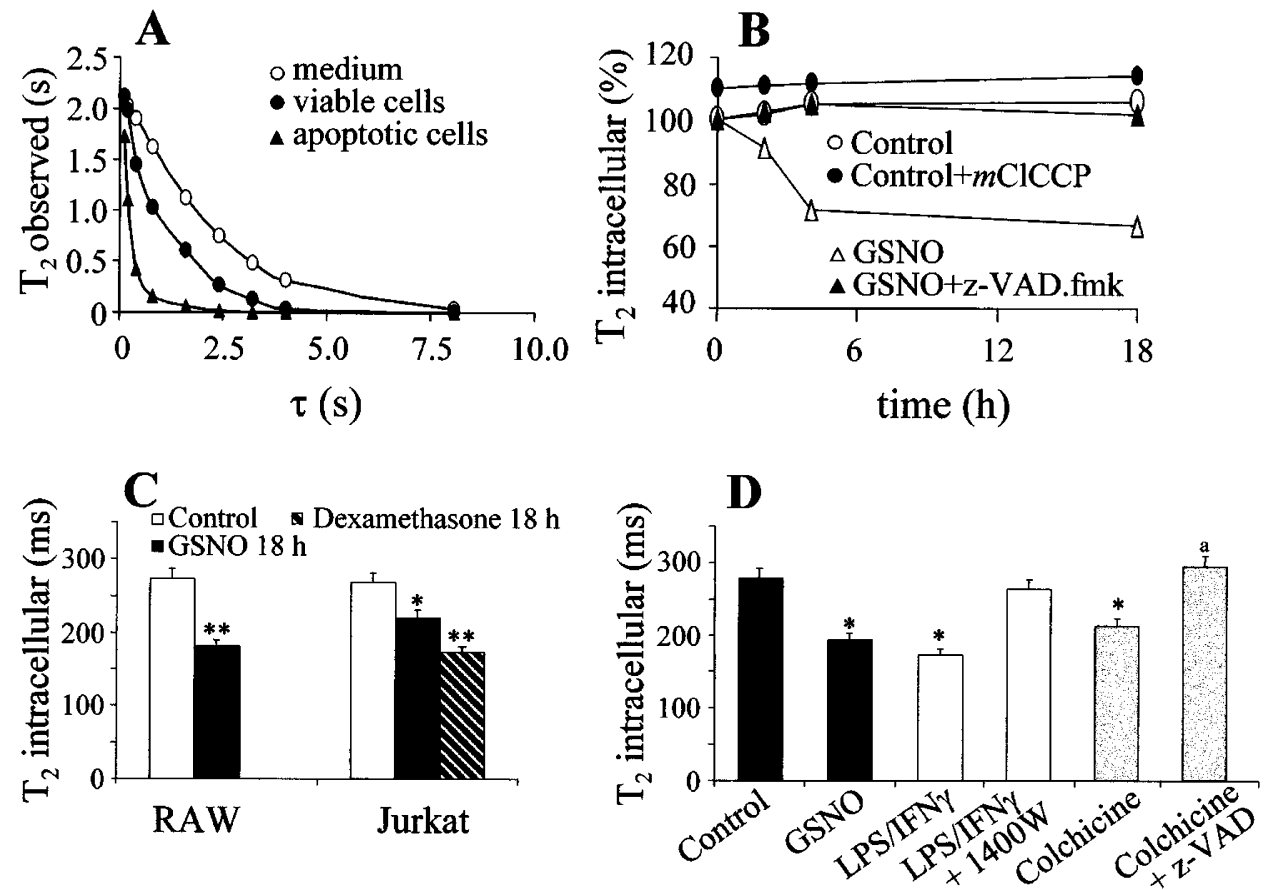

Figure 2 Changes of $T_{2}$ values in apoptotic cells. Cells were scraped off the dishes, kept at ca. $0.5 \mathrm{~g} / \mathrm{ml}$ and immediately analyzed by ${ }^{1} \mathrm{H}$ NMR spectroscopy. The transversal equilibrium magnetization recoveries ( $\mathrm{T}_{2}$ observed) were determined by the Carr-Purcell-Meiboom-Gill sequence (A). The time course of intracellular $\mathrm{T}_{2}$ changes in cells treated with GSNO in the absence or presence of $20 \mu \mathrm{M} \mathrm{z-VAD.fmk} \mathrm{was} \mathrm{calculated} \mathrm{and} \mathrm{expressed} \mathrm{as} \mathrm{percentage} \mathrm{of} \mathrm{the} \mathrm{T}_{2}$ value of control cells $(287 \pm 23 \mathrm{~ms})$. Control cells were challenged at the sampling times shown with $10 \mu \mathrm{M}$ of the mitochondrial uncoupling agent $m$-chlorophenylhydrazone carbonylcyanide $(m \mathrm{CICCP})$ and after $10 \mathrm{~min} \mathrm{~T}_{2}$ values were determined $(B)$. In parallel with RAW 264.7 cells, Jurkat T cells were incubated for $18 \mathrm{~h}$ with $1 \mathrm{mM}$ GSNO or $1 \mu \mathrm{M}$ dexamethasone and intracellular $\mathrm{T}_{2}$ was determined (C). The changes of $\mathrm{T}_{2}$ were determined in RAW 264.7 cells activated with LPS (200 ng/ml) and IFN $\gamma(20 \mathrm{U} / \mathrm{ml})$, and incubated with or without $100 \mu \mathrm{M} 1400 \mathrm{~W}$. Treatment of cells for $4 \mathrm{~h}$ with $10 \mu \mathrm{M}$ colchicine decreased $\mathrm{T}_{2}$, whereas in the presence of $20 \mu \mathrm{M} \mathrm{z-}$ VAD.fmk $T_{2}$ values remained unchanged (D). Results show a representative experiment $(\mathbf{A}, \mathbf{B})$ and the mean \pm S.E. of four experiments $(\mathbf{C}, \mathbf{D})$. ${ }^{*} P<0.005$, ${ }^{* \star} P<0.001$ with respect to the corresponding control conditions; ${ }^{a} P<0.001$ with respect to the colchicine condition

In addition to the changes in the relaxation times of intracellular water, a statistically significant decrease in the ADC values was observed in apoptotic cells when compared with viable counterparts (Figure 3A). Moreover, the intracellular $A D C$ values increased in activated cells treated with $1400 \mathrm{~W}$ reflecting a lower basal percentage of apoptotic cells. To establish a parallelism between intracellular $T_{2}$ and ADC values and water dynamics in polyol media those parameters were analyzed in solutions of PEG and glycerol prepared in culture medium. ${ }^{19,20}$ As Figure 3B,C shows, $T_{2}$ values decreased in glycerol solutions higher than 5\% (w:w), whereas PEG was more effective with $A D C$ values.

The decrease of $T_{2}$ values in apoptotic cells suggests a restricted rotational movement of water and, possibly, an increase in the overall hydrophobicity of the intracellular medium or within defined cytoplasmic environments. This was investigated by analyzing the fluorescence intensity and distribution of the hydrophobic probes Bodipy and Nile red in macrophages. ${ }^{31,32}$ When apoptotic cells were incubated with Bodipy, a lipidinteracting fluorescent molecule, the accumulation of the probe in the cytosol increased as deduced by confocal microscopy (Figure 4A). This was confirmed by flow cytometry of cells treated for $18 \mathrm{~h}$ with LPS and IFN $\gamma$, or for $8 \mathrm{~h}$ with GSNO. This higher fluorescence was specific for the apoptotic phenotype since it was observed neither in activated cells treated with z-VAD.fmk nor in NOS-2 expressing cells incubated with 1400W (Figure 4C). As Figure 4B shows, the fluorescence of Nile red increased in apoptotic cells, with areas of intense accumulation in the cytoplasm. The flow cytometric results paralleled those obtained by confocal microscopy. This accumulation of the probes in the cytoplasm after caspase activation suggests the presence of more hydrophobic environments, compatible with a restriction in water relaxation.

\section{The decrease in intracellular $\mathrm{T}_{2}$ was observed after caspase activation}

To establish the sequential changes of cell parameters in the course of apoptosis, RAW 264.7 cells were treated with GSNO, and analysis of apoptotic events was performed at different times: The release of cytochrome $c$ from the mitochondrial to the cytosol was measured by Western blot; the binding of annexin $V$ and the incorporation of propodium iodide as markers of apoptosis were carried out by flow cytometry; intracellular $\mathrm{T}_{2}$ values were determined by ${ }^{1} \mathrm{H}$ NMR using the Carr-Purcell-Meiboom-Gill sequence $;^{8}$ and the 

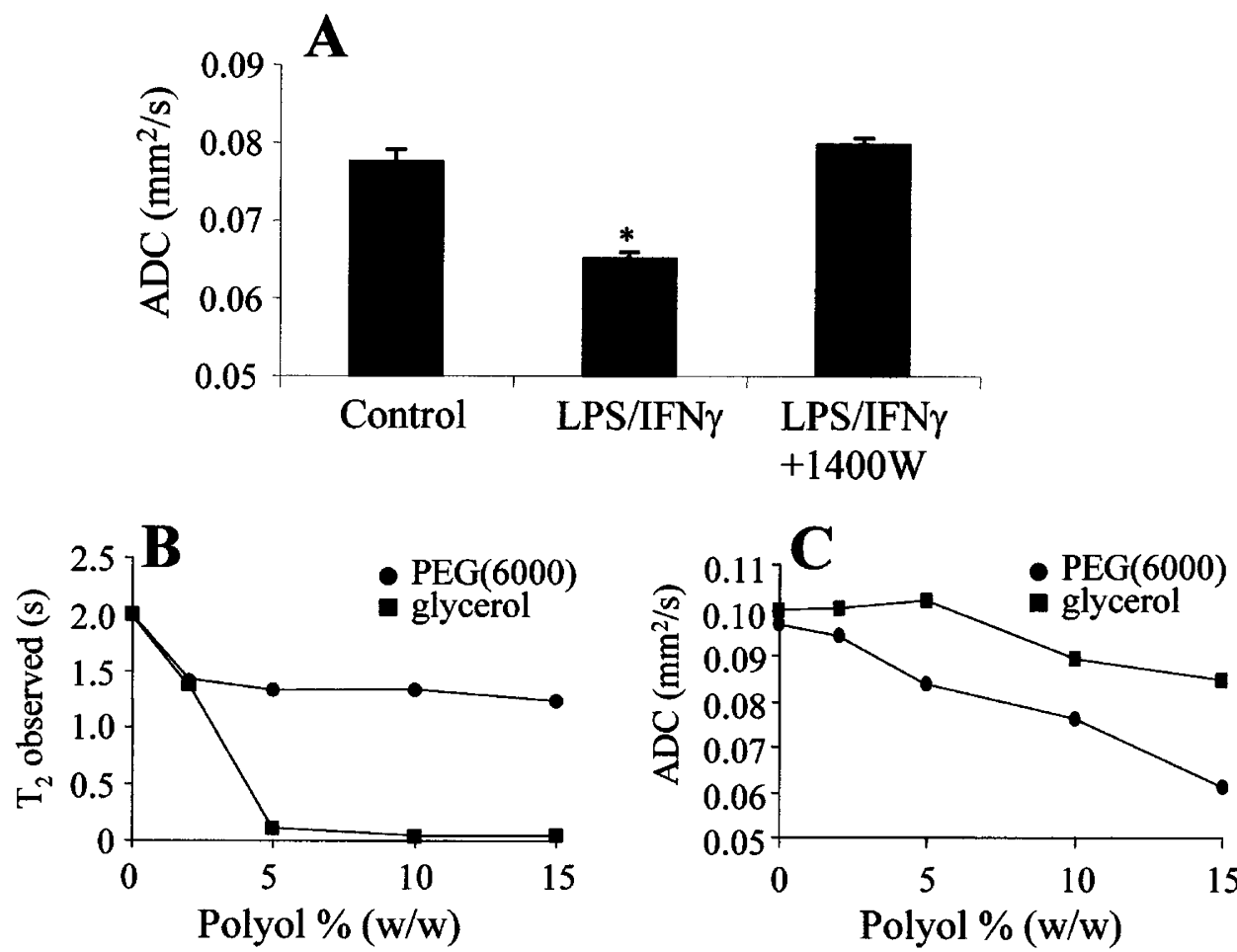

Figure 3 Apparent diffusion coefficient (ADC) of RAW 264.7 cells undergoing apoptosis. The apparent self-diffusion coefficient of water in cell suspensions (ADC) was determined using the pulse field gradient $(\mathbf{A})$. The $T_{2}$ and $A D C$ values of a solution of glycerol and PEG 6000 in culture medium were determined as indicated for the cell suspension $(\mathbf{B}, \mathbf{C})$. Results show the mean \pm S.E. of three experiments $(\mathbf{A})$. ${ }^{\star} P<0.01$ with respect to the control condition

A

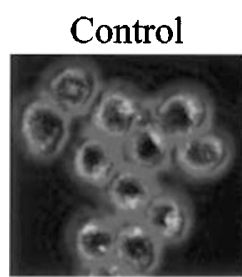

B

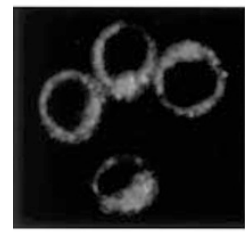

LPS+IFN $\gamma$

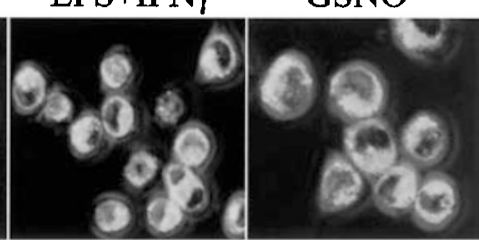

Bodipy

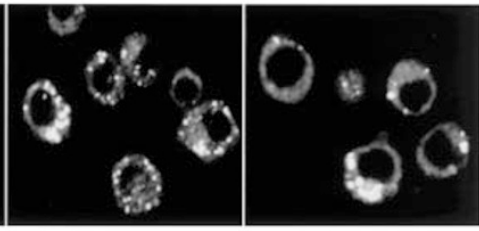

Nile red
$\mathbf{C}$
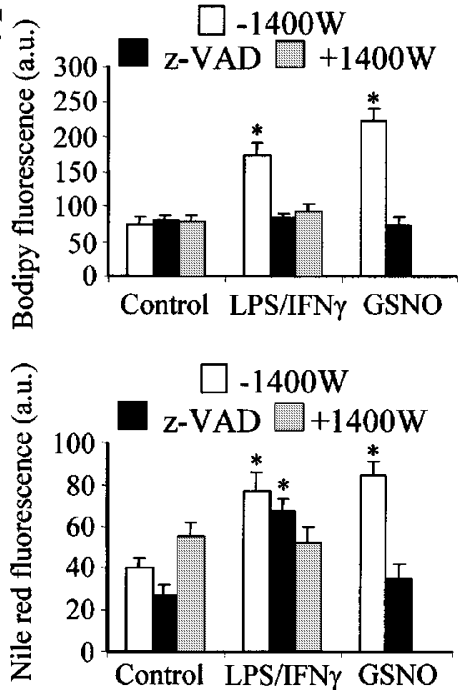

Figure 4 Fluorescence distribution of hydrophobic probes in macrophages undergoing apoptosis. RAW 264.7 cells were incubated for $14 \mathrm{~h}$ with LPS and IFN $\gamma$ or with GSNO and then treated with $2 \mu \mathrm{M}$ Bodipy or $0.3 \mu \mathrm{M}$ of Nile red. The intracellular distribution of fluorescence was determined by confocal microscopy $(\mathbf{A}, \mathbf{B})$ and by flow cytometry $(\mathbf{C})$ to obtain a quantitative evaluation of the increase of fluorescence. Results show the mean \pm S.E. of four experiments. ${ }^{*} P<0.01$ with respect to the control condition for each probe

activity of caspase 3 was measured in cytosolic extracts using a fluorogenic substrate. As Figure 5 shows, the changes of $T_{2}$ paralleled those of caspase activation and preceded exposure of phosphatidylserine residues (annexin $\mathrm{V}$ positive cells) and propidium iodide staining.

\section{Discussion}

The results reported in this work provide new insights on the physical changes occurring in apoptotic cells. The identifica- 


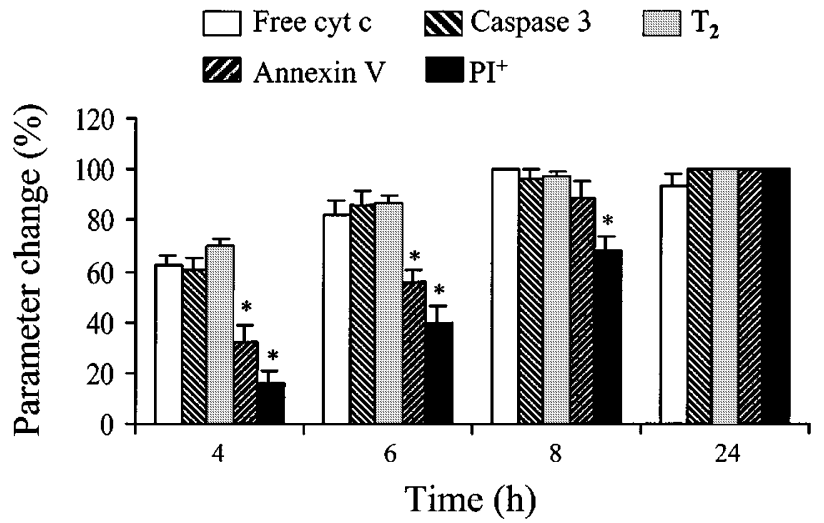

Figure 5 Time course of changes in parameters related with apoptosis. RAW 264.7 cells were stimulated with $1 \mathrm{mM}$ GSNO and at $4,6,8$ and $24 \mathrm{~h}$ the release of cytochrome $c$ from the mitochondrial to the cytosol, the activity of caspase 3 , the $T_{2}$ times, the binding of annexin $V$ and the staining with propidium iodide $(\mathrm{PI})$ were determined. Results show the mean $\pm \mathrm{S}$.E. of four experiments, and are expressed as percentage of the maximal effect. ${ }^{*} P<0.01$ with respect to the $T_{2}$ value. The differences between caspase 3 activity, free cytochrome $c$ and $T_{2}$ are not statistically significant

tion of cytoplasmic domains with increased hydrophobicity suggests the existence of regions in which water is more ordered; a condition that favors protein - protein interactions and that might alter the catalytic properties of enzymes when compared to viable cells. ${ }^{33}$ Indeed, normotonic cell shrinkage due to cell-volume regulation has been considered a major hallmark of apoptosis. ${ }^{34}$ The kinetics of the changes in $T_{2}$ and the inhibition exerted by z-VAD.fmk on this process suggest that the alterations of water structure are dependent on caspase activation, probably preceding other apoptotic events such as DNA fragmentation through caspaseactivated DNAse (CAD) activation. Our results further indicate that the loss of cytoskeletal organization is not sufficient to account for the changes in $T_{2}$, but rather the increase in the molar concentration of peptides produced by caspase-dependent proteolysis and/or the aforesaid changes in cell volume ${ }^{34}$ are responsible for the decrease in this parameter. In addition to the decrease of $\mathrm{T}_{2}$, the diffusion rate of water (ADC) was also reduced in apoptotic cells. Using solutions of polyols, we confirmed that $T_{2}$ and $A D C$ are not linked processes. PEG is very efficient decreasing ADCs, whereas glycerol affects mainly $\mathrm{T}_{2}$.

Changes in the NMR spectra of intracellular water have been described in the course of physiological and pathological processes. ${ }^{17}$ For example, spin-lattice relaxation time $\left(T_{1}\right)$ and spin-spin relaxation time $\left(T_{2}\right)$ have been measured during the cell-cycle division in synchronized fibroblasts activated with EGF and in transformed mouse 10T1/2 cells. $T_{1}$ values were insensitive or poorly sensitive to the phase of the cell cycle, but $T_{2}$ increased at $G_{1}$ when compared with cells in $S$ phase. Parallel changes were observed in ADC, and these results have been interpreted as reflecting alterations in the diffusion of intracellular water through non-homogeneous local magnetic field gradients, these effects also influencing $T_{2}$ values. ${ }^{35,36}$ In addition to this, decreases in ADCs of water and small metabolites were measured under hypoxia in brain slices, ${ }^{37}$ and in models of intact/relaxed and skinned/rigor muscle fibers of frog skeletal muscle, where the intracellular water located in the overlap region of actin and myosin filaments was less structured in the rigor state than in the relaxed situation. ${ }^{38}$

Data on $A D C$ and $T_{2}$ values have previously been studied in apoptotic cells. Induction of apoptosis in BT4C rat glioma cells by glanciclovir in the course of thymidine kinase therapy increased intracellular viscosity and reduced by $50 \%$ of $A D C$, an effect that was interpreted as a reduction in the hydrodynamic radii of macromolecules, presumably due to the occurrence of apoptotic death. ${ }^{39}$ In this way, our data provide a direct correlation between apoptosis and changes of $\mathrm{T}_{2}$ and $\mathrm{ADC}$ by using pharmacological inhibitors of caspases, and establish a kinetic link between $T_{2}$ changes, manifestation of apoptotic events and how these alterations in water dynamics and accessibility affect the polarity of the intracellular environment. Indeed, alterations in $T_{2}$ parallel caspase 3 activation and precede other characteristic events of the apoptotic phenotype, such as annexin $\mathrm{V}$ binding and propidium iodide staining, suggesting that detection of decreased $\mathrm{T}_{2}$ values by magnetic resonance methods in inflammatory areas observed in ischemic episodes or in tumoral processes could provide an early, non-invasive, indicator of apoptosis in vivo.

Finally, it is tempting to speculate on the relevance of the ordering of water in terms of activation of caspases, perhaps as a mechanism contributing to more efficient processing of these proteases. As recently reviewed by Salvesen et al., ${ }^{40}$ the unusual property of caspase zymogens to autoprocess into active forms might benefit from a more structured water organization as observed for proteins in polyol solutions where the protein-protein interactions are notably enhanced. This has been described as the induced-proximity model of caspase activation. ${ }^{40}$ Additionally, intracellular water ordering may have more general biochemical implications affecting other fundamental processes including enzyme catalysis, metabolic regulation and changes in the translational and transcriptional machinery. Extrapolation of the observed alterations in the ${ }^{1} \mathrm{H}$ NMR spectra of an apoptotic cell in culture to pathological circumstances analyzed by Magnetic Resonance Imaging might help to unravel the extension and further progression of apoptotic events in intact organisms.

\section{Materials and Methods}

\section{Chemicals}

Reagents were from Sigma (St Louis, MO, USA), Roche (Mannheim, Germany) and Merck (Darmstadt, Germany). LPS was from $S$. typhimurium (Sigma). Serum and media were from Biowhittaker (Walkersville, MD, USA). Polyethyleneglycol (6000) and glycerol were dissolved $(w: w)$ in culture medium. Bodipy and Nile red were from Molecular Probes (Eugene, OR, USA).

\section{Cell culture}

RAW 264.7 cells were obtained from ATCC and correspond to a murine macrophage cell line. RAW 264.7 cells were seeded at $10^{5}$ \% 
$\mathrm{cm}^{2}$ in RPMI 1640 medium supplemented with $2 \mathrm{mM}$ glutamine, $10 \%$ FCS and $50 \mathrm{~g} / \mathrm{ml}$ of penicillin, streptomycin and gentamicin, respectively. When required, macrophages were scraped off the dishes and maintained at $0.5 \mathrm{~g} / \mathrm{ml}$ in RPMI 1650 medium containing $0.5 \%$ of FCS, and immediately used for ${ }^{1} \mathrm{H}$ NMR analysis. Jurkat $\mathrm{T}$ cells were cultured and treated under identical conditions.

\section{Preparation of cell extracts}

Cells $\left(2 \times 10^{6}\right)$ were washed with PBS, scraped off the dishes and collected by centrifugation. Cell pellets were homogenized in $100 \mathrm{I}$ of buffer A (10 mM HEPES, pH 7.9; 1 mM EDTA, 1 mM EGTA, 100 mM $\mathrm{KCl}, 1 \mathrm{mM}$ DTT, $0.5 \mathrm{mM}$ phenyl-methyl-sulfonyl fluoride, $2 \mu \mathrm{g} / \mathrm{ml}$ aprotinin, $10 \mu \mathrm{g} / \mathrm{ml}$ leupeptin, $2 \mu \mathrm{g} / \mathrm{ml}$ tosyl-L-lysine chloromethyl ketone, $5 \mathrm{mM} \mathrm{NaF}, 1 \mathrm{mM} \mathrm{NaVO}$, and $10 \mathrm{mM} \mathrm{Na} \mathrm{MoO}_{4}$ ). After $10 \mathrm{~min}$ at $4{ }^{\circ} \mathrm{C}$ Nonidet $\mathrm{P}-40$ was added $(0.5 \% \mathrm{v} / \mathrm{v})$ and the tubes were vortexed (15 s) and centrifuged (Eppendorf microcentrifuge) for $15 \mathrm{~min}$. The supernatants were stored at $-80^{\circ} \mathrm{C}$ (soluble extracts). Protein content was determined using the Bio-Rad protein assay. Cell fractionation was carried out at $4^{\circ} \mathrm{C}$.

\section{Characterization of proteins by Western blot}

Soluble protein extracts were size-separated in 10\% SDS-PAGE. The gels were blotted onto a Hybond-P membrane (Amersham) and incubated with anti-NOS-2 and anti-cytochrome $c$ (Santa Cruz Laboratories, Santa Cruz, CA, USA) Abs. When the release of cytochrome $c$ from the mitochondria to the cytosol was determined, the cell suspension $\left(2 \times 10^{6}\right)$ was maintained in $250 \mu$ l of PBS to which an equal volume of $0.3 \mathrm{M}$ sucrose and $15 \mathrm{mg}$ of digitonin in PBS were added and incubated for $10 \mathrm{~min}$ at $4^{\circ} \mathrm{C}$. After centrifugation, the supernatant was used to determine the presence of soluble cytochrome $c$. The blots were revealed by enhanced chemiluminescence following the manufacturer instructions (Amersham). Different exposure times of the films were used to ensure that bands were not saturated. Quantification of the films was performed by laser densitometry (Molecular Dynamics, Kemsing, UK).

\section{Determination of NO synthesis}

NO release was determined spectrophotometrically by the accumulation of nitrite in the medium (phenol red-free) as described. ${ }^{15}$ NOS-2 activity was inhibited with $1400 \mathrm{~W} .^{24}$

\section{Analysis of apoptosis by flow cytometry and internucleosomal DNA degradation}

In vivo propidium iodide staining was performed after incubation of the cells with the indicated stimuli in the presence of $0.005 \% \mathrm{PI}$. Cells were resuspended and assayed in a FACScan cytometer (BD Biosciences). The analysis of apoptotic cells was performed using a dot plot of the forward scatter against the PI fluorescence and the apoptotic nature of the cells gated in the different regions was confirmed after sorting and analysis of DNA laddering. ${ }^{25,41}$ Binding of annexin $\mathrm{V}$ (Roche) to phosphatidylserine residues of apoptotic cells was analyzed by flow cytometry. ${ }^{25}$

\section{Confocal microscopy}

RAW cells were grown on cover slips and incubated for the indicated periods with various stimuli. Analysis of the fluorescence distribution of the hyrophobic probes Bodipy $(2 \mu \mathrm{M})$ and Nile red $(0.3 \mu \mathrm{M})$ was carried out after 20 min of incubation with these molecules. The cells were visualized using an MRC-1024 confocal microscope (Bio-Rad), and the fluorescence was measured and electronically evaluated. Laser sharp software (Bio-Rad) was used to determine the relative intensity of the fluorescence per pixel, and the percentage of cytosolic localization. Alternatively, cells were analyzed by flow cytometry to determine the percentage of cells with increased probe fluorescence.

\section{${ }^{1} \mathrm{H}$ NMR analysis}

Adherent cells (RAW 264.7) were scraped off the dishes and concentrated by centrifugation to reach ca. $0.5 \mathrm{~g} / \mathrm{ml}$. $T_{2}$ values of the extracellular medium $\left(T_{2 e}\right)$ or cell suspensions $\left(T_{2 o b s}\right)$ were determined by the Carr-Purcell-Meiboom-Gill spin-echo sequence. ${ }^{19}$ Intracellular $T_{2}\left(T_{2 i}\right)$ was calculated from the observed $T_{2}$ value in the cell suspension $\left(\mathrm{T}_{20 \mathrm{bs}}\right)$, the relative contributions of intracellular $\left(\mathrm{V}_{\mathrm{i}}\right)$ and extracellular $\left(\mathrm{V}_{\mathrm{e}}\right)$ volumes to the total volume $\left(\mathrm{V}_{\mathrm{t}}\right)$, and the extracellular $T_{2}$ value $\left(T_{2 e}\right)$ as measured in the extracellular medium without cells $\left(\mathrm{V}_{\mathrm{i}} / \mathrm{T}_{2 \mathrm{i}}=\mathrm{V}_{\mathrm{t}} / \mathrm{T}_{2 \mathrm{obs}}-\mathrm{V}_{\mathrm{e}} / \mathrm{T}_{2 \mathrm{e}}\right)$.

The intracellular diffusion coefficient $\left(A D C_{i}\right)$ was determined from $A D C_{\text {obs }}$, the relative contributions of intracellular $\left(V_{i}\right)$ and extracellular volumes $\left(V_{e}\right)$ to the total volume $\left(V_{t}\right)$ and the extracellular $A D C_{e}$ determined in the resuspension medium without cells $\left(\mathrm{V}_{\mathrm{i}} /\right.$ $\left.A D C_{i}=V_{t} A D C_{o b s}-V_{e} / A D C_{e}\right)$.

\section{Caspase 3 assay}

The activity of caspase 3 was measured fluorometrically using as substrate $\mathrm{N}$-acetyl-DEVD-7-amino-4-methylcoumarin (a preferred substrate of caspases 3 and 7), following the instructions of the supplier (BD Biosciences). Z-VAD.fmk was used to inhibit caspase activity and to ensure the specificity of the reaction. The linearity of the caspase assay was determined over a $30 \mathrm{~min}$ reaction period.

\section{Acknowledgements}

The authors thank Dr. María Angeles Moro, Dr. Sislar Cook and Dr. Ignacio Rodríguez-Crespo for critical reading of the manuscript and to $\mathrm{E}$ Lundin for help in the preparation of the text. This work was supported by grants 2FD97-1432 and PM98-0120 from Comisión Interministerial de Ciencia y Tecnología (Spain), and 08.3/007.2/99 from Comunidad de Madrid (Spain).

\section{References}

1. MacMicking J, Zie QW and Nathan C (1997) Nitric oxide and macrophage function. Annu. Rev. Immunol. 15: 323-350

2. Dugas B, Debre P and Moncada S (1995) Nitric oxide, a vital poison inside the immune and inflammatory network. Res. Immunol. 146: 664-670

3. Bogdan C, Rollinhoff M and Diefenbach A (2000) Reactive oxygen and reactive nitrogen intermediates in innate and specific immunity. Curr. Opin. Immunol. 12: $64-76$

4. Albina JE andReichner JS (1998) Role of nitric oxide in mediation of macrophage cytotoxicity and apoptosis. Cancer Metastasis Rev. 17: 39-53

5. Anderson GP (1996) Resolution of chronic inflammation by therapeutic induction of apoptosis. Trends. Pharmacol. Sci. 17: 438-442

6. Williams GT (1994) Programmed cell death: a fundamental protective response to pathogens. Trends Microbiol. 2: 463-464

7. Nathan C (1995) Natural resistance and nitric oxide. Cell 82: 873-876

8. Savill J (1997) Apoptosis in resolution of inflammation. J. Leukoc. Biol. 61: 375380 
9. Bosca L and Hortelano S (1999) Mechanisms of nitric oxide-dependent apoptosis: involvement of mitochondrial mediators. Cell Signal. 11: 239-244

10. Thompson CB (1995) Apoptosis in the pathogenesis and treatment of disease. Science 267: $1456-1462$

11. Thornberry NA and Lazebnik Y (1998) Caspases: enemies within. Science 281 : $1312-1316$

12. Green DR (1998) Apoptotic pathways: the roads to ruin. Cell 94: 695-698

13. Nicholson DW (1999) Caspase structure, proteolytic substrates, and function during apoptotic cell death. Cell Death Differ. 6: 1028-1042

14. Bossy-WetzelE, NewmeyerDD and Green DR (1998) Mitochondrial cytochrome c release in apoptosis occurs upstream of DEVD-specific caspase activation and independently of mitochondrial transmembrane depolarization. EMBO J.17: $37-49$

15. Hortelano S, Alvarez AM and Bosca L (1999) Nitric oxide induces tyrosine nitration and release of cytochrome $c$ preceding an increase of mitochondria transmembrane potential in macrophages. FASEB J. 13: 2311-2317

16. Zheng TS, Hunot S, Kuida K and Flavell RA (1999) Caspase knockouts: matters of life and death. Cell Death Differ. 6: 1043-1053

17. Hakumäki JM and Kauppinen RA (2000) $1 \mathrm{H}$ NMR visible lipids in the life and death of cells. Trends Biochem. Sci. 8: 357-362

18. Hakumäki JM, Poptani H, Sandmair AM, Yla-Herttuala S and Kauppinen RA (1999) ${ }^{1} \mathrm{H}$ MRS detects polyunsaturated fatty acid accumulation during gene therapy of glioma: implications for the in vivo detection of apoptosis. Nat. Med. 5 : $1323-1327$

19. Lopez-Beltran EA, Mate MJ and Cerdan S (1996) Dynamics and environment of mitochondrial water as detected by 1 H NMR. J. Biol. Chem. 271: 10648-10653

20. Garcia-Perez Al, Lopez-Beltran EA, Kluner P, Luque J, Ballesteros $P$ and Cerdan S (1999) Molecular crowding and viscosity as determinants of translational diffusion of metabolites in subcellular organelles. Arch. Biochem. Biophys. 362: 329-338

21. Bryant RG (1996) The dynamics of water-protein interactions. Annu. Rev. Biophys. Biomol. Struct. 25: 29-53

22. Bhakoo KKand Bell JD (1997) The application of NMR spectroscopy to the study of apoptosis. Cell. Mol. Biol. 43: 621-629

23. Terenzi F, Diaz-Guerra MJ, Casado M, Hortelano S, Leoni S and Bosca L (1995) Bacterial lipopeptides induce nitric oxide synthase and promote apoptosis through nitric oxide-independent pathways in rat macrophages. J. Biol. Chem. 270: $6017-6021$

24. Laszlo F and Whittle BJ (1997) Actions of isoform-selective and non-selective nitric oxide synthase inhibitors on endotoxin-induced vascular leakage in rat colon. Eur. J. Pharmacol. 334: 99-102

25. Hortelano S, López-Collazo A and Boscá L (1999) Protective effect of cyclosporin A and FK506 from nitric oxide-dependent apoptosis in activated macrophages. Br. J. Pharmacol. 126: 1139-1146

26. Green DR and Reed JC (1998) Mitochondria and apoptosis. Science 281 $1309-1312$
27. Hortelano S, Dallaporta B, Zamzami N, Hirsch T, Susin SA, Marzo I, Bosca L and Kroemer G (1997) Nitric oxide induces apoptosis via triggering mitochondrial permeability transition. FEBS Lett. 410: 373-377

28. Kroemer G, Dallaporta B and Resche-Rigon M (1998) The mitochondrial death/ life regulator in apoptosis and necrosis. Annu. Rev. Physiol. 60:619-642

29. Fadeel B, Zhivotovsky B and Orrenius S (1999) All along the watchtower: on the regulation of apoptosis regulators. FASEB J. 13: 1647-1657

30. Kromer G, Boscá L, Zamzami N, Hortelano S and Martinez-AC (1997) Detection of apoptosis and apoptosis associated alterations. The Immunological Methods Manual. ed. R. Lefkovitz, 14.2: 1111-1125

31. Ferretti A, Knijn A, Iorio E, Pulciani S, Giambenedetti M, Molinari A, Meschini S, Stringaro A, Calcabrini A, Freitas I, Strom R, Rancia G and Podo F (1999) Biophysical and structural characterization of ${ }^{1} \mathrm{H}$-NMR-detectable mobile lipid domains in NIH-3T3 fibroblasts. Biochim. Biophys. Acta 1438: 329-348

32. Gocze PM and Freeman DA (1994) Factors underlying the variability of lipid droplet fluorescence in MA-10 Leydig tumor cells. Cytometry 17: 151-158

33. Knoll D and Hermans J (1983) Polymer-protein interactions. Comparison of experiment and excluded volume theory. J. Biol. Chem. 2583: 5710-5715

34. Maeno E, Ishizaki Y, Kanaseki T, Hazama A and Okada Y (2000) Normotonic cell shrinkage because of disordered volume regulation is an early prerequisite to apoptosis. Proc. Natl. Acad. Sci. USA 97: 9487-9492

35. Belfi CA, Medendorp SV and Ngo FQ (1991) The dependence of proton longitudinal and transverse relaxation times on cell-cycle phase: mouse MCAtransformed 10T1/2 TCL-15 cells. Magn. Reson. Med. 22: 379-393

36. Callahan DE, Deamond SF, Creasey DC, Trapane TL, Bruce SA, Ts'o PO and Kan LS (1991) NMR studies of intracellular water at $300 \mathrm{MHz}$ : $\mathrm{T}_{2}$-specific relaxation mechanisms in synchronized or EGF-stimulated cells. Magn. Reson. Med. 22: 68-80

37. Hakumäki JM, Pirttila TR and Kauppinen RA (2000) Reduction in water and metabolite apparent diffusion coefficients during energy failure involves cationdependent mechanisms. A proton nuclear magnetic resonance study of rat cortical brain slices. J. Cereb. Blood Flow Metab. 20: 405-411

38. Yamada T (1998) 1H-NMR spectroscopy of the intracellular water of resting and rigor frog skeletal muscle. Adv. Exp. Med. Biol. 453: 145-154

39. Hakumäki JM, Poptani H, Puumalainen AM, Loimas S, Paljarvi LA, Yla-Herttuala $S$ and Kauppinen RA (1998) Quantitative ${ }^{1} \mathrm{H}$ nuclear magnetic resonance diffusion spectroscopy of BT4C rat glioma during thymidine kinase-mediated gene therapy in vivo: identification of apoptotic response. Cancer Res. 58: 3791-3799

40. Salvesen GS and Dixit VM (1999) Caspase activation: the induced-proximity model. Proc. Natl. Acad. Sci. USA 96: 10964-10967

41. Genaro AM, Hortelano S, Alvarez A, Martinez C and Bosca L (1995) Splenic B lymphocyte programmed cell death is prevented by nitric oxide release through mechanisms involving sustained Bcl-2 levels. J. Clin. Invest. 95: 1884-1890 